\title{
Cost Benefit Analysis of Self-Optimized Hybrid Solar- Wind-Hydro Electrical Energy Supply as compared with HOMER Optimization
}

\author{
Amevi Acakpovi \\ Accra Polytechnic \\ P.O BOX: GP561
}

\author{
Essel Ben Hagan \\ Accra Institute of Technology \\ P.O. BOX: AN-19782
}

\author{
Mathias Bennet Michael \\ Accra Polytechnic \\ P.O BOX: GP561
}

\begin{abstract}
The purpose of this paper is to evaluate the cost benefit of a self-optimized solar-wind-hydro hybrid energy supply and to compare the outcome with a similar optimization done with the HOMER software. In reality HOMER optimization software has long been used for hybrid system optimization and many do consider it as the reference software for any optimization related to hybrid energy systems. However, due to some few lack of flexibility in the setting-up of constraints and also the ignorance of the true optimization approaches used by the HOMER, it has become necessary to develop selfoptimized algorithms based on rigorous mathematical models. One of these self-optimized models, developed in a previous study, was presented in this paper and was tested with data collected at Accra, Ghana. Results show that the cost of electricity proposed by the HOMER, $0.307 \$ / \mathrm{kWh}$, is slightly lower than the one obtained through the self-optimized method, $0.442 \$ / \mathrm{kWh}$. Moreover looking at the dynamism of selecting different sources to achieve the optimization at a lower rate for the user, more credit is given to the developed method than the HOMER because the self-optimization method gives more priority to the wind turbine than the solar plant due to the higher electricity cost of solar $(0.64 \$ / \mathrm{kWh})$. It was however observed that the HOMER software does the opposite in terms of priority. Moreover the probability of unmet load is lower with the self-optimized method than the HOMER result which consists of a big contribution because it is a major quality measure for hybrid systems to always satisfy the load request.
\end{abstract}

\section{General Terms}

Hybrid energy, Cost optimization, Matlab programming, Homer Optimization

\section{Keywords}

Solar Energy, Wind Energy, Hydro Energy, Cost optimization, Matlab Simulation, HOMER optimization

\section{INTRODUCTION}

HOMER is known to be the global standard for microgrid optimization. According to [1], HOMER is a computer model that simplifies the task of designing hybrid renewable microgrids, whether remote or attached to a larger grid. HOMER's optimization and sensitivity analysis algorithms help to evaluate the economic and technical feasibility of a large number of technology options and to account for variations in technology costs and energy resource availability. However, HOMER software does not give a clear account on the analytical approach of the optimization technique adopted to solve most microgrid optimization problems. In addition, HOMER does not provide flexibility to a user to set his optimization problem with some special constraints like the case where individual prices of different sources of electricity are already fixed on market. In a nutshell, despite its name and global influence on hybrid renewable energy market, HOMER does not satisfy all needs for hybrid renewable microgrid optimization and this is the reason why many other scientists investigated several other approaches often based on rigorous mathematical methods.

Existing optimization of solar, wind, hydro, and diesel generator were handled with the approach of particle swarm optimizations. In this regard, Amer (2013), [2] proposed an optimization of renewable hybrid energy system for cost reduction using Particle Swarm Optimization (PSO) approach. Bansal \& al. (2010), [3] used a Meta Particle Swarm Optimization technique to perform the cost optimization of a hybrid wind, solar and storage battery. In addition, Ram et al. (2013), [4], used metaheuristic particle swarm optimization approach to develop the optimal design of a stand-alone hybrid power generation plant comprising of wind turbine generators, PV panels and storage batteries connected to a diesel generator for additional needs. Furthermore, Trazouei (2013), [5] also used the imperialist competitive algorithm, particle swarm optimization and ant colony optimization to determine the optimum configuration of a hybrid wind, solar and diesel energy supply. More advanced optimization approaches were proposed by Sharma \& al. (2014), [6] who developed a new methodology, hybrid GAPSO (HGAPSO), a combination of GA and PSO approaches to achieve cost optimization of an off-grid hybrid energy system (HES). GA is known to suffer from low speed convergence while PSO suffers premature convergence but the new algorithm proposed by [6] has tremendously improved on the speed and brought about a global convergence. Idoumghar \& al. (2011), [7], presents a novel hybrid evolutionary algorithm that combines Particle Swarm Optimization (PSO) and Simulated Annealing (SA) algorithms that basically work on the premature defect of simple PSO.

On the other hand, Ekren et al. (2009), [8] used a commercial simulation software named ARENA 12.0 to perform the simulation of $\mathrm{PV} /$ wind integrated hybrid energy system with battery storage, under various loads. Wei (2008), [9] further used the approach of genetic algorithm to determine the optimum sizing of a PV-Wind hybrid system. Also, Ashok (2007), [10] designed an optimized model to add wind, solar and micro-hydro hybrid energy. The algorithm senses wind velocity, solar radiation and load requirement to actually control the hybrid system. Power generated by each sources have been modelled and fed to an analytical model. Results help in sizing and choosing the best components to provide the optimal power.

It is extremely important to realize that most of these modern ways of optimizing hybrid energy system are targeting the sizing of system which relates to capital cost but do not necessarily provide a comprehensive analysis on levelized cost of electricity which implies the cost of electricity for the 
hybrid system. There is no clear evidence on how all these modern techniques have improved upon the reduction of electricity fees which should be the main target of hybrid energy supply. HOMER software actually fills this gap by providing a comprehensive analysis based on cost but also fail to bring clarity on the rigorous optimization method adopted. Moreover, there is no clear basis to evaluate the cost of hybrid system provided by HOMER because of the unavailability of other tools to compare with.

The first part of this paper presents the available resources and load requirement for the site that will be used for testing. This is followed by a deep review of a solution proposed to a cost optimization problem of solar-wind-hydro hybrid energy system developed by Acakpovi et al. (2015), [11]. The paper, further implements a solution to the same problem with the Homer software and finally compare the results obtained from both solutions to the optimization problems.

\section{METHODOLOGY}

\subsection{Available Resources and Energy Demand}

Secondary data were collected at Accra-Ghana using the RETSCREEN Plus software. The location of the site used is latitude 5.6 North, Longitude -0.2 East and elevation $68 \mathrm{~m}$. Solar radiation and wind profile were also collected from the RETSCREEN Plus software for the year 2013. The profile of available wind speed at the selected location as well as solar radiation profile are shown in table 1 and respectively plotted in figure 1 and figure 2.

Table 1: Wind Speed and Solar Radiation Profile of Accra-Ghana (2013)

\begin{tabular}{|l|c|c|}
\hline Month & $\begin{array}{c}\text { Solar } \\
\text { Radiation }\end{array}$ & Wind Speed \\
\hline Jan & 4.10 & 2.6 \\
\hline Feb & 4.59 & 2.6 \\
\hline March & 5.21 & 2.6 \\
\hline April & 5.08 & 2.6 \\
\hline May & 5.02 & 2.1 \\
\hline June & 3.97 & 2.1 \\
\hline July & 3.70 & 4.6 \\
\hline Aug & 3.84 & 5.1 \\
\hline Sept & 4.59 & 5.1 \\
\hline Oct & 5.19 & 2.6 \\
\hline Nov & 4.79 & 2.6 \\
\hline Dec & 3.86 & 2.1 \\
\hline \\
\hline
\end{tabular}

Fig 1. Wind Speed Profile for Accra-Ghana (2013)

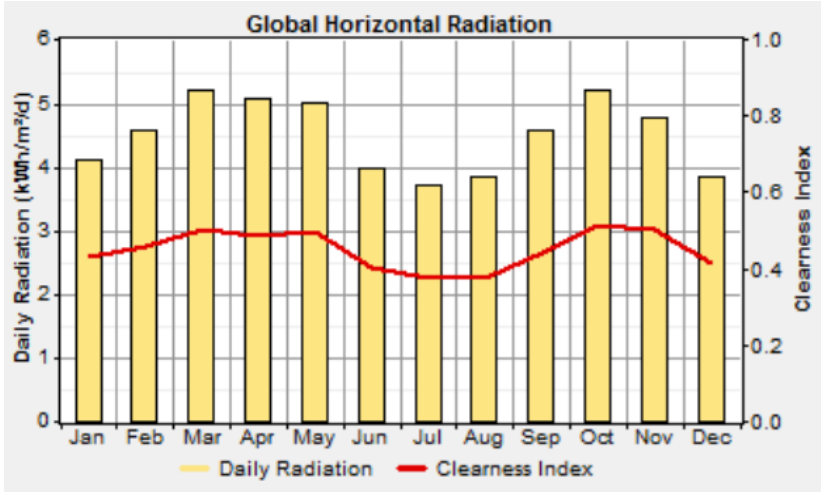

Fig 2. Solar Radiation Profile for Accra-Ghana (2013)

Besides, for the water resources, an average water flow of $1001 / \mathrm{s}$ was considered with some random variability for different month. The profile is shown in figure 3 .

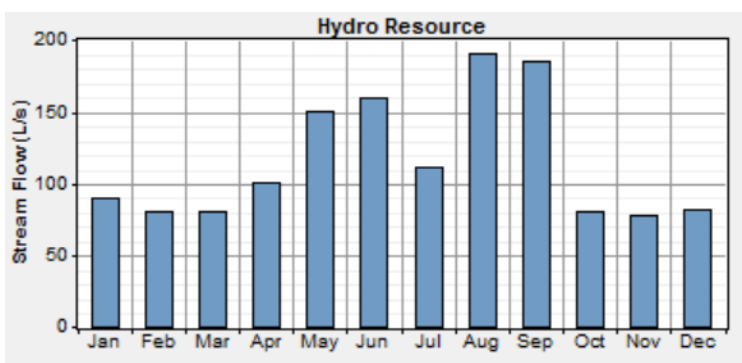

Fig 3. Average Water Flow per month

On the other hand, the load profile is created on a hypothetical basis. An average load of $6 \mathrm{~kW}$ appears throughout a day with some random variability accounting for an average of $250 \mathrm{Wh}$ consumption per day. Figure 4 depicts the load profile

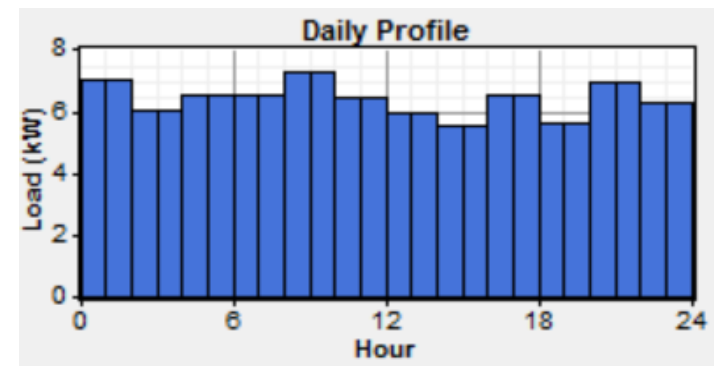

Fig 4. Hourly Load Profile

\subsection{Review of Optimization Problem and its Proposed Solution}

\subsubsection{Adopted Models of Individual Sources}

The paragraph below presents a brief model of power generated by the following individual sources: solar, wind, and mini-hydro generators.

\section{Analytical model of Solar Energy Generation}

According to previous works done by Acakpovi et al. (2013), [12], Villalva (2010), [13], Ramos-Paja (2010), [14], and Tsai (2008), [15], the model of power generated by a PV module can be given by the formula below:

$$
\mathrm{P}(\mathrm{t})=\mathrm{n}_{\mathrm{r}}\left[1-\beta\left(\mathrm{T}_{\mathrm{c}}-\mathrm{T}_{\text {cref }}\right)\right] \cdot \mathrm{A} \cdot \mathrm{G}(\mathrm{t})
$$

Where $n_{r}$ is the reference module efficiency, $T_{\text {cref }}$ is reference cell temperature in degree Celsius, $\mathrm{A}\left(\mathrm{m}^{2}\right)$ is the PV generator area and $G(t)$ is the solar irradiation in tilted module plane 
$\left(\mathrm{Wh} / \mathrm{m}^{2}\right), \beta$ is the temperature coefficient, $\mathrm{Tc}$ is the cell effective temperature.

\section{Analytical model of Wind Energy Generation}

The model of wind power can be derived from works done by Khajuria (2012), [16], Abbas (2010), [17], and Acakpovi (2014), [18] as follow:

$$
\mathrm{P}_{\mathrm{m}}(\mathrm{t})=\frac{1}{2} \rho \mathrm{AC}_{\mathrm{p}} \mathrm{V}_{\mathrm{w}}^{3}(\mathrm{t})
$$

Where:

- $\quad \mathrm{C}_{\mathrm{p}}$ is the coefficient of performance also called power coefficient

- $\quad$ A is the swept area by the turbine' blades $\left(\mathrm{m}^{2}\right)$

- $\quad \rho$ is the air density $\left(\mathrm{kg} / \mathrm{m}^{3}\right)$

- $\quad V_{w}$ is the wind speed $(\mathrm{m} / \mathrm{s})$

- Analytical model of Mini-hydro generators

The general formula for the determination of hydraulic power is shown by Fuchs et al. (2011), [19], Hernandez et al. (2012), [20],Naghizadeh et al. (2012), [21] as follow:

$$
\mathrm{P}_{\mathrm{m}}=\eta_{\mathrm{t}} \rho \mathrm{gHQ}(\mathrm{t})
$$

Where: $\mathrm{P}_{\mathrm{m}}$ is the mechanical power produced at the turbine shaft (Watts), $\rho$ is the density of water $\left(1000 \mathrm{~kg} / \mathrm{m}^{3}\right)$, $g$ is the acceleration due to gravity $\left(9.81 \mathrm{~m} / \mathrm{s}^{2}\right), \mathrm{Q}$ is the water flow rate passing through the turbine $\left(\mathrm{m}^{3} / \mathrm{s}\right), \mathrm{H}$ is the effective pressure head of water across the turbine $(\mathrm{m})$ and $\mathrm{y}_{\mathrm{t}}$ is the efficiency of the turbine.

\subsubsection{Assumptions}

With reference to Acakpovi \& al. (2015), [11] the following assumptions are made:

- $\quad$ Each module is considered independent at the construction level and therefore their various cost of electricity will be estimated separately.

- $\quad$ There exist numbers $\mathrm{N}_{\mathrm{s}}, \mathrm{N}_{\mathrm{w}}$ and $\mathrm{N}_{\mathrm{h}}$ representing respectively the total number of solar plant, wind power plant and mini-hydro power plant respectively in existence.

\subsubsection{Optimization Problem Formulation}

Considering the unit costs of electricity $\mathrm{C}_{\mathrm{us}}, \mathrm{C}_{\mathrm{uw}}, \mathrm{C}_{\mathrm{uh}}$, generated respectively by the solar, wind and hydropower plants, the cost of electricity generated by the hybrid energy system over a period of time $\mathrm{T}$ was expressed in the previous paper, [11], as follows:

$$
\mathrm{CE}=\mathrm{a}_{\mathrm{s}} \mathrm{C}_{\mathrm{us}} \mathrm{nAGT}+\mathrm{a}_{\mathrm{w}} \mathrm{C}_{\mathrm{uw}} \frac{1}{2} \rho \mathrm{AC}_{\mathrm{p}} \mathrm{V}_{\mathrm{w}}^{3} \mathrm{~T}+\mathrm{a}_{\mathrm{h}} \mathrm{C}_{\mathrm{uh}} \rho \mathrm{gHQT}
$$

The unit cost of electricity is further evaluated based on equation 5 below:

$$
\mathrm{C}_{\mathrm{u}}=\frac{\mathrm{C}_{\mathrm{c}} \cdot \mathrm{CRF}+\mathrm{C}_{\mathrm{o}}}{\mathrm{E}_{\mathrm{T}}}
$$

Where $\mathrm{C}_{\mathrm{c}}$ represents the capital cost of investment, CRF is the capital recovery factor, $\mathrm{C}_{\mathrm{o}}$ is the operation and maintenance cost and $\mathrm{E}_{\mathrm{T}}$ is the total energy generated over a year.

The objective function is given as follow

Minimize CE subjected to the following constraints:
1. The power generated by the hybrid system should meet the demand at any given time as expressed below:

$$
\mathrm{a}_{\mathrm{s}} \cdot \mathrm{P}_{\mathrm{S}}(\mathrm{t})+\mathrm{a}_{\mathrm{w}} \cdot \mathrm{P}_{\mathrm{W}}(\mathrm{t})+\mathrm{a}_{\mathrm{h}} \cdot \mathrm{P}_{\mathrm{H}}(\mathrm{t}) \geq \mathrm{P}_{\mathrm{d}}(\mathrm{t})
$$

2. The total power generated should be within range of minimum and maximum power that can be generated

$\mathrm{P}_{\min } \leq \mathrm{a}_{\mathrm{s}} \cdot \mathrm{P}_{\mathrm{S}}(\mathrm{t})+\mathrm{a}_{\mathrm{w}} \cdot \mathrm{P}_{\mathrm{W}}(\mathrm{t})+\mathrm{a}_{\mathrm{h}} \cdot \mathrm{P}_{\mathrm{H}}(\mathrm{t}) \leq \mathrm{P}_{\max }$

3. Variables should also stay between bounds as follow

$$
\left\{\begin{array}{l}
0 \leq \mathrm{a}_{\mathrm{s}} \leq \mathrm{N}_{\mathrm{s}} \\
0 \leq \mathrm{a}_{\mathrm{w}} \leq \mathrm{N}_{\mathrm{w}} \\
0 \leq \mathrm{a}_{\mathrm{h}} \leq \mathrm{N}_{\mathrm{h}} \\
0 \leq \mathrm{a}_{\mathrm{s}}, \mathrm{a}_{\mathrm{w}}, \mathrm{a}_{\mathrm{h}} \\
\mathrm{G}_{\min } \leq \mathrm{G} \leq \mathrm{G}_{\max } \\
\mathrm{V}_{\mathrm{wmin}} \leq \mathrm{V}_{\mathrm{w}} \leq \mathrm{V}_{\mathrm{wmax}} \\
\mathrm{Q}_{\min } \leq \mathrm{Q} \leq \mathrm{Q}_{\max }
\end{array}\right.
$$

With the assumption that the irradiation $\mathrm{G}$, the wind velocity $\mathrm{V}_{\mathrm{w}}$ and the water flow $\mathrm{Q}$ are all constant during the period $\mathrm{T}$, the problem was considered as a linear optimization function subjected to linear inequalities constraints.

\subsubsection{Proposed Solution}

The solution to the above optimization problem is constructed around the linprog function of Matlab and can be described by the following algorithm.

1. Initialize an index variable to $\mathrm{N}$ that will serve for iteration.

2. Get the input load data, wind velocity, solar irradiation and hydro data (water flow and total head) as well as necessary data to evaluate the unit cost of electricity per individual sources

3. Calculate the power generated by individual sources of renewable energy generator using the models described above

4. Create decision variables for indexing

5. Define lower and upper bounds for all variables

6. Define linear equality and linear inequality constraints

7. Define the objective function

8. Solving the linear optimization problem with the function linprog of Matlab

9. Save result

10. Increase the index $\mathrm{N}$ by 1

11. If index $\mathrm{N}$ is less than or equal to 12 (for the twelve months in a year), repeat processes from 2 to 10

12. Display result

13. Stop.

\subsection{Implementation with HOMER}

\section{Software}

The general scheme of the proposed hybrid system is shown in figure 5. Also, table 2 summarizes the main cost 
configurations of the system implemented in the HOMER software.

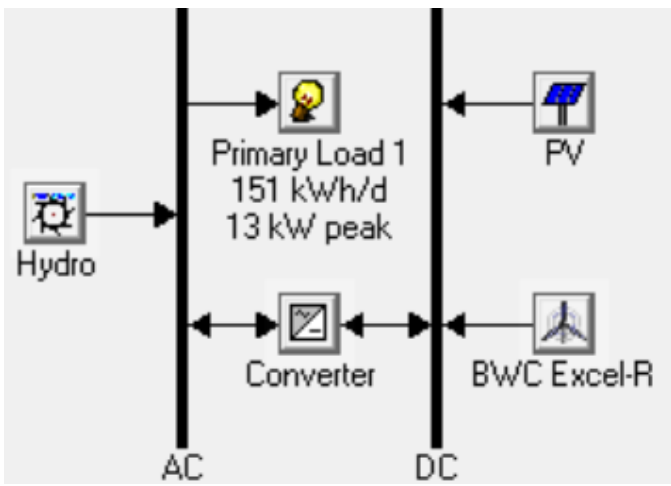

Fig 5. Proposed Solar-Wind-Hydro Hybrid Electrical Supply

Table 2: Details of capital, replacement and O\&M costs

\begin{tabular}{|l|l|l|l|}
\hline $\begin{array}{l}\text { List of } \\
\text { component }\end{array}$ & $\begin{array}{l}\text { Capital } \\
\text { Cost }\end{array}$ & $\begin{array}{l}\text { Replacement } \\
\text { Cost }\end{array}$ & $\begin{array}{l}\text { O\&M } \\
\text { Cost }\end{array}$ \\
\hline $\begin{array}{l}\text { Solar PV System } \\
(5 \mathrm{~kW})\end{array}$ & 25000 & 25000 & 0 \\
\hline $\begin{array}{l}\text { Wind Turbine } \\
(7.5 \mathrm{~kW})\end{array}$ & 18750 & 18750 & 10 \\
\hline Hydro (1 kW) & 12000 & 6000 & 1000 \\
\hline $\begin{array}{l}\text { Converter (15 } \\
\mathrm{kW})\end{array}$ & 2100 & 2100 & 10 \\
\hline
\end{tabular}

The configuration of the system components including the solar plant, wind turbine, hydro plant and the converters are illustrated in figure 6,7,8 and 9 respectively. The capital cost of $\$ 5 / \mathrm{kW}$ was considered for the solar system with no maintenance fees because solar panels require very insignificant maintenance. The system lifetime is fixed to 20 years. A $7.5 \mathrm{~kW}$ wind turbine was selected with the same lifetime of 20 years. The hydro plant was also configured with an average water flow of 1001/s and a total head of about $10 \mathrm{~m}$. The converter block is mainly used for the inverter function and its efficiency is set to $90 \%$.

Enter at least one size and capital cost value in the Costs table. Include all costs associated with the PV (photovollaic) system, including modules, mounting hardware, and installation. As it searches for the optimal systen HOMER considers each $\mathrm{PV}$ array capacity in the Sizes to Consider table

Note that by default, HOMER sets the slope value equal to the latitude from the Solar Resoucce Inputs window. Hold the pointer over an element or click Help for more information.

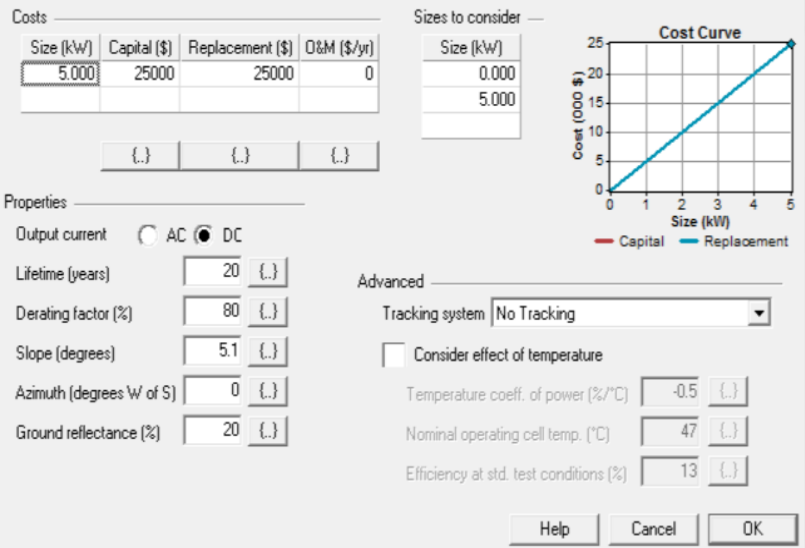

Fig 6. Configuration of Solar Plant

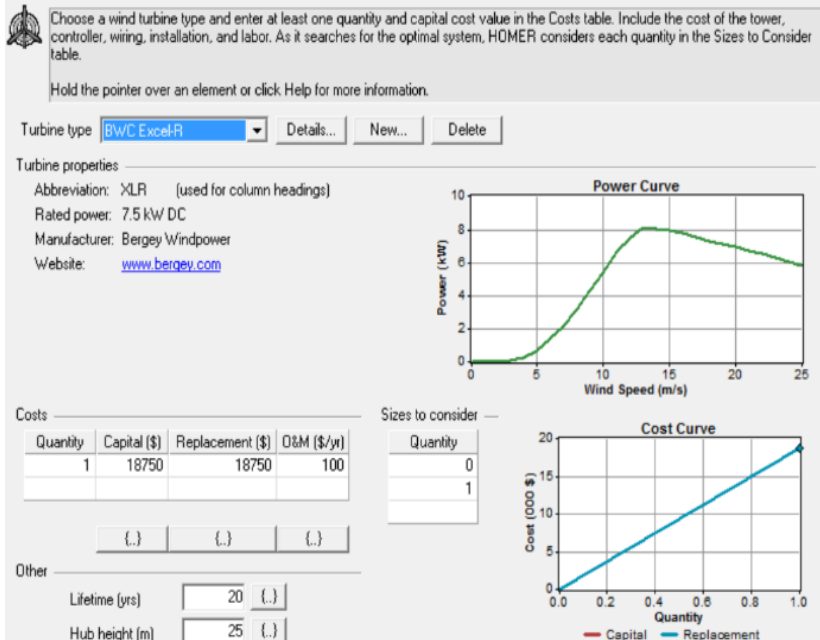

Fig 7. Configuration of Wind Turbine

20. HOMER models run-of-river hydro installations. Enter the capital cost, available head, an turbine design flow rate. For Economics values, include the civil works and all costs associated with the hydro sustem. HOMER calculates the nominal power from the available head, design flow rate, and efficiency.

Hold the pointer over an element or click Help for more information. Economics

\begin{tabular}{|c|c|}
\hline Capital cost (\$) & $\overline{12000}$ \\
\hline Replacement cost (\$) & 6000 \\
\hline $0 \& M \operatorname{cost}(\$ / y r)$ & 1000 \\
\hline Lifetime (years) & 25 \\
\hline
\end{tabular}

Turbine



Intake pipe

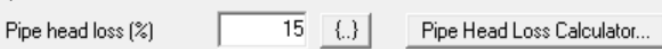
Systems to conside

Simulate systems both with and without the hydro turbine

- Include the hydro turbine in all simulated systems

$$
\text { Help | Cancel }
$$

\section{Fig 8. Configuration of Hydropower Plant}

A converter is required for systems in which $D C$ components serve an $A C$ load or vice-versa. $A$ converter can be an inverter (DC to $A C)$, rectifier $(A C$ to $D C)$, or both

Enter at least one size and capital cost value in the Costs table. Include all costs associated with the converter, such a hadware and labor As it searches for the optimal system. HOMER considers each converter capacity in the Sizes to Consider table. Note that all references to converter size or capacity refer to inverter capacity.

Hold the pointer over an element or click Help for more information.

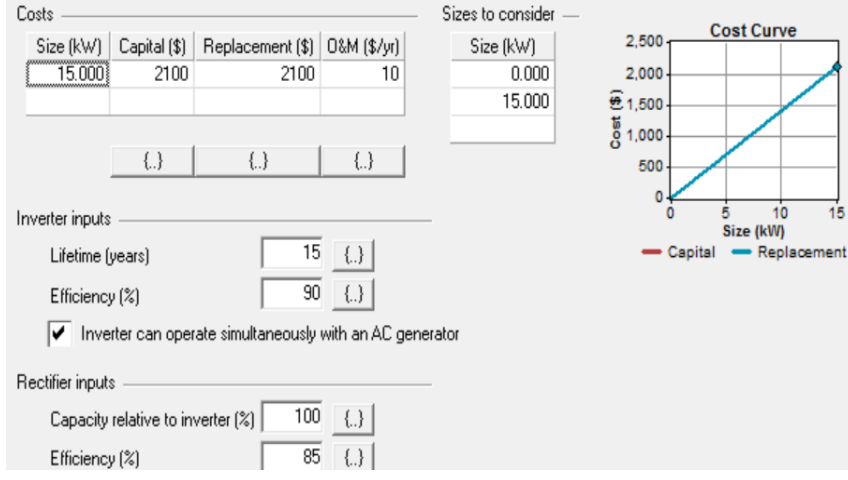

Fig 9. Configuration of Converter 


\section{RESULT AND DISCUSSION}

Simulation results were obtained from both the proposed algorithm (implemented with Matlab) and also the implementation done with the Homer software. Figure 10 and 11 show the contribution of individual plants to the total energy supplied using respectively the self-developed optimization algorithm and the HOMER software.

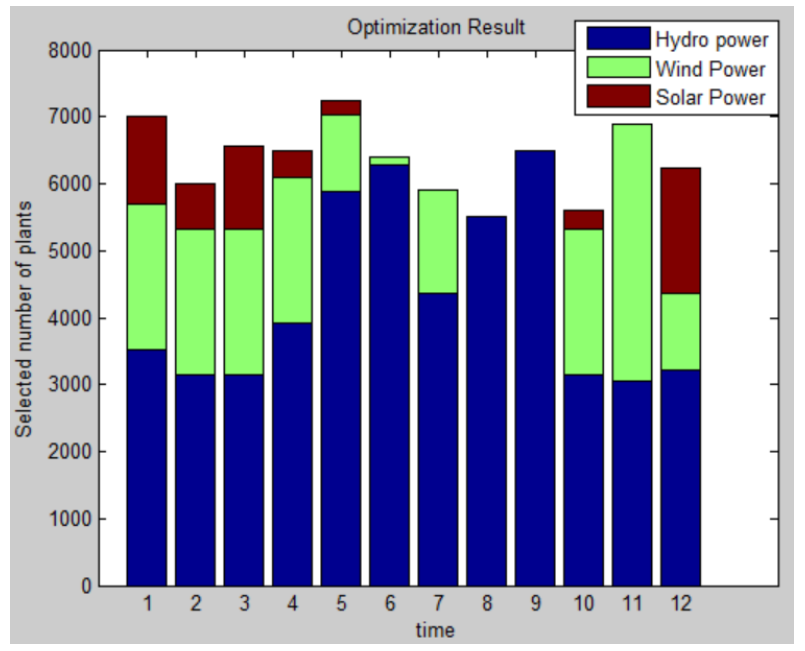

Fig 10. Contribution of individual plants to the total energy supplied using the self-optimized method

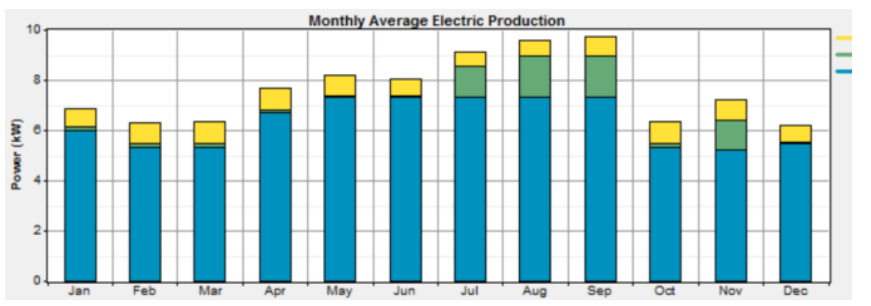

Fig 11. Contribution of individual plants to the total energy supplied using the HOMER

These graphs show actually the dynamic operation of the optimization methods in selecting the adequate sources and level of their contribution that brings the optimum cost. It is observed in both cases that the hydropower plant has been selected and used throughout the year. This is justified due to the cost of generating hydro which is the least as compared to the counterpart solar and wind. In reality, the unit cost of electricity estimated by the self-optimized algorithm were $0.64 \$ / \mathrm{kWh}, 0.52 \$ / \mathrm{kWh}, 0.36 \$ / \mathrm{kWh}$ respectively for the solar, wind and hydro energy. Subsequently, the other two sources becomes additive to compensate the load in case the hydro contribution is not enough to satisfy the request. In cases where the hydro energy produced can supply the load request, it is solely used as in the case of the eighth and ninth month (figure 10). It is also observed that the wind energy comes in second priority as its cost is lower than the solar one with respect to the self-optimized algorithm. However, wind speed are very low in the considered location therefore making the wind energy production to be very small.

Besides, solar is the most expensive and most available that comes in when both the hydro and wind resources are exhausted. Surprisingly, the solar is rather put in second priority in place of the wind with the HOMER optimization. With the HOMER result, the solar energy is often used in case of deficit of hydro energy and it is only when the solar is exhausted that the wind energy is solicited. Back to the settings, it can be observed that the capital for solar is $\$ 25000$ with $\$ 0$ for O\&M and the wind capital is $\$ 18750$ with $\$ 10$ for O\&M per year. With these facts, we therefore believe that the proposed algorithm approaches this aspect of the optimization in a better manner than the HOMER does.

Moreover, it must be observed that the dynamic contribution of individual sources do not follow strictly the same pattern in both cases of optimization and this is due to the random variability of energy resources (solar radiation, wind speed, available water flow) and load request that do not necessarily follow the same pattern in both cases.

Furthermore, figure 12 and 13 show the cost of electricity and the energy supply versus the load requested for both methods.

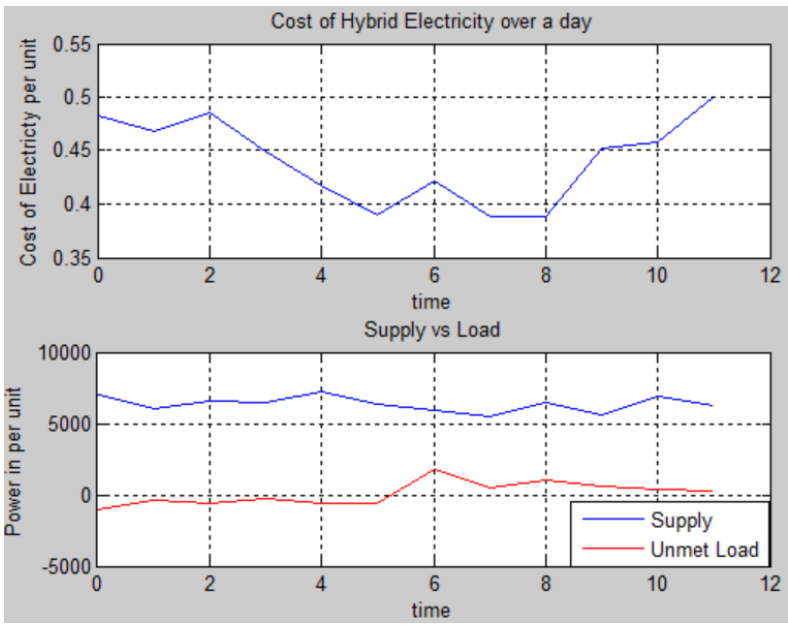

Fig 12. Cost of Electricity and Supply vs Load request using the self-optimized algorithm

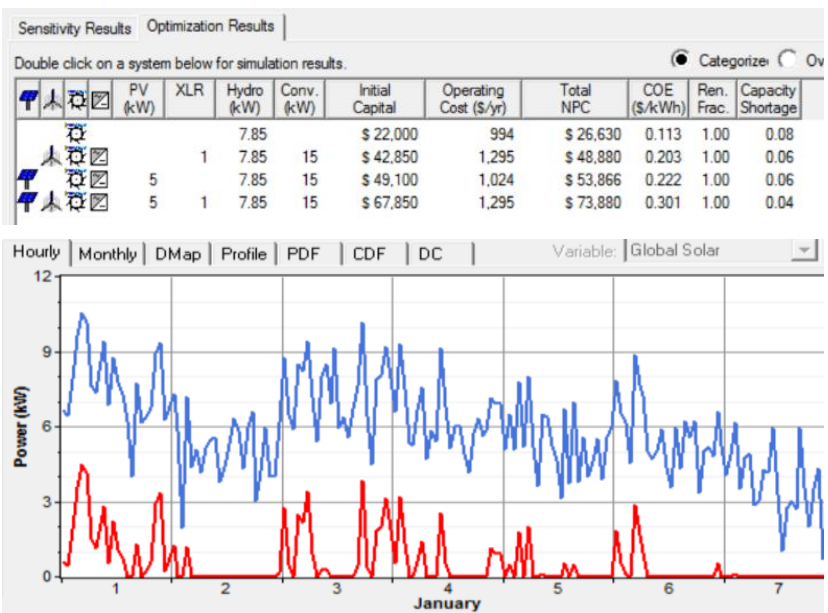

Fig 13. Cost of Electricity and Supply vs Load request using the self-optimized algorithm

Figure 13 shows that the HOMER estimates an initial capital cost of $\$ 67850$ with an operating cost of $\$ 1,295$ per year for the proposed hybrid solar-wind-hydro power plant. The cost of electricity which is the main economic output of the HOMER optimization software is found to be $0.307 \$ / \mathrm{kWh}$. On the other hand, figure 12 shows that the cost of electricity varies averagely around $0.442 \$ / \mathrm{kWh}$ with a peak of 0.5 $\$ / \mathrm{kWh}$. In general the cost estimated by the developed algorithm is roughly higher than the one estimated by the HOMER for the same conditions. This can be beneficial for the investor as it may reduce the payback period of the system 
while keeping the electricity cost affordable and acceptable to consumers.

Furthermore, a basic constraint for the optimization was to always satisfy the load request. This was achieved brilliantly in the second part of figure 12 where the unmet load is almost always closed to zero. The same situation is depicted in the second part of figure 13 where the curve in red represent the unmet load using the HOMER software. It appears clearly that majority of the load is satisfy with the first method as compared to the HOMER optimization.

\section{CONCLUSION}

In summary, this paper dealt with a comparative analysis of cost optimization of hybrid energy system comprising of solar, wind and hydro plants, using a self-developed algorithm and the HOMER optimization software. The optimization methods were presented and tested over the same data and results were compared. It was revealed that the self-optimized system shows more dynamism and rational in the selection of different sources as compared to the HOMER. The cost of electricity is however higher with the self-optimized method $(0.442 \$ / \mathrm{kWh})$ than the HOMER $(0.307 \$ / \mathrm{kWh})$ and this brings about a quicker payback period which is a big motivation for investors. Finally, the two methods were compared on the basis of satisfaction of the load request. It appears that the percentage of unmet load is higher with the HOMER than the self-optimized method. Cost optimization of hybrid system is very useful to reduce the cost of electricity while keeping profit in acceptable range. HOMER is the standard software used to achieve such optimization but this paper proposes a counter method that brings pertinent differences in the result obtained. Henceforth, there is a merit in researching more advanced optimization method to reassess the cost benefit of Hybrid energy supplies.

\section{APPENDIX}

\subsection{Matlab Code Showing the Self- Proposed Solution}

\section{clear all}

clf

clc

$\%$ General Data

$\mathrm{t}=[0: 11]$

P_load $=[7000,6000,6550,6500,7250,6400,5900,5500,6500,56$ 00,6890,6240];

P_rload=randi ([5500 7300],1,12);

$\mathrm{Q}=[90,80,80,100,150,160,111,190,185,80,78,82]$;

$\%$ Data on irradiation and wind speed at Accra

$\mathrm{G}=[4.1,4.59,5.21,5.08,5.02,3.97,3.7,3.84,4.59,5.19$,

$4.79,3.86]$

$\mathrm{VW}_{\mathrm{W}}=[2.6,2.6,2.6,2.6,2.1,2.1,4.6,5.1,5.1,2.6,4.6,2.1]$;

$\%$ Loading initial data needed for the computation of unit cost

$\% \ldots$

$\%$ End of data

$\%$ Computing unit cost of electricity per each source

Cans $=\mathrm{Ccs} * \mathrm{CRF}+\mathrm{Cos}$;

$\mathrm{Canw}=\mathrm{Ccw} * \mathrm{CRFw}+\mathrm{Cow}$

$\mathrm{Canh}=\mathrm{Cch} * \mathrm{CRFh}+\mathrm{Coh}$;

$\mathrm{Cus}=\mathrm{Cans} / \mathrm{Es}$

$\mathrm{Cuw}=\mathrm{Canw} / \mathrm{Ew}$

$\mathrm{Cuh}=\mathrm{Canh} / \mathrm{Eh}$

for $\mathrm{i}=1: 12$

\%Input parameters

P_load(i); \%Load power request
$\%$ P_min=; \% Minimum power generated by the Hybrid System

P_max $=20 \mathrm{e} 3 ; \%$ Maximum power generated by the Hybrid System

$\%$ Defining number of existing plants

$\mathrm{Ns}=.$. ;

$\mathrm{Nw}=. . ;$

$\mathrm{Nh}=.$. ;

$\%$ Solar parameters

$\mathrm{n}=0.2 ; \%$ efficiency

As $=2 ; \%$ Solar Area metre square

$\mathrm{G}(\mathrm{i}) ; \%$ Solar Irradiation

$\mathrm{T}=1 ; \quad \%$ Duration $\mathrm{T}$ in hours

$\%$ Wind parameters

ro_a $=1.23 ; \%$ air density

Aw $=\mathrm{pi}^{*} 3^{\wedge} 3 ; \%$ Area swept by the blades in metre square

$\mathrm{Cp}=16 / 27 ; \%$ Betz Coefficient

Vw(i); \%Wind velocity

$\%$ Hydro parameters

ro_wa $=1 ; \%$ water density

$\mathrm{g}=9.81 ; \%$ gravity acceleration

$\mathrm{H}=4 ; \quad \%$ Total head

$\%$ Computing power generated by each source

$\mathrm{Ps}(\mathrm{i})=\mathrm{n} * \mathrm{As} * \mathrm{G}(\mathrm{i}) * 1000$;

$\mathrm{Pw}(\mathrm{i})=(1 / 2) *$ ro_a*Aw* $\mathrm{Cp} * \mathrm{Vw}(\mathrm{i})^{\wedge} 3$;

$\mathrm{Ph}(\mathrm{i})=$ ro_wa*g*H*Q(i);

$\%$ Defining the optimization problem

variables $=\{$ 'as','aw','ah' $\}$;

$\mathrm{N}=$ length(variables);

$\%$ create variables for indexing

for $\mathrm{v}=1: \mathrm{N}$

eval([variables $\{\mathrm{v}\},{ }^{\prime}=$ ', num2str(v),';']);

end

$\%$ Defining the lower bounds

$\mathrm{lb}=$ zeros(size(variables));

$\mathrm{lb}([\mathrm{as}, \mathrm{aw}, \mathrm{ah}])=[0,0,0]$;

$\%$ Defining the upper bounds

$\mathrm{ub}=\operatorname{Inf}($ size (variables $))$;

$\mathrm{ub}([\mathrm{as}, \mathrm{aw}, \mathrm{ah}])=[\mathrm{Ns}, \mathrm{Nw}, \mathrm{Nh}]$;

$\%$ Entrying linear inequality constraints

$\mathrm{A}=\operatorname{zeros}(2,3)$;

$\mathrm{A}(1,[$ as, aw, ah] $)=[-\mathrm{Ps}(\mathrm{i}),-\mathrm{Pw}(\mathrm{i}),-\mathrm{Ph}(\mathrm{i})]$;

$\mathrm{b}(1)=-\mathrm{P} \_$load $(\mathrm{i})$;

$\mathrm{A}(2,[$ as $, \mathrm{aw}, \mathrm{ah}])=[\mathrm{Ps}(\mathrm{i}), \mathrm{Pw}(\mathrm{i}), \mathrm{Ph}(\mathrm{i})]$;

$\mathrm{b}(2)=\mathrm{P} \_$max

\%Linear Equality Constraints

Aeq=[];

beq=[];

\%Objective Function

$\mathrm{f}=$ zeros(size(variables) $)$;

$\mathrm{f}([$ as aw ah $])=[\mathrm{Cus} * \mathrm{Ps}(\mathrm{i}) * \mathrm{~T}$ Cuw*Pw(i)*T Cuh*Ph(i)*T];

\%Solving the problem with linprog

[x fval] $=\operatorname{linprog}(\mathrm{f}, \mathrm{A}, \mathrm{b}$, Aeq, beq,lb,ub);

for $\mathrm{d}=1: \mathrm{N}$

fprintf('\%12.2f $\backslash t \% s \backslash n ', x(d)$, variables $\{d\})$;

end;

$\operatorname{aso}(i)=x(1), \operatorname{awo}(i)=x(2), \operatorname{aho}(i)=x(3)$;

P_Supply(i)=aso(i)*Ps(i)+awo(i)*Pw(i)+aho(i)*Ph(i);

end ost $(i)=$ fval/P_Supply(i);

ao $=[$ aho. $* \mathrm{Ph} ;$ awo. $* \mathrm{Pw} ;$ aso. $* \mathrm{Ps}]$;

figure(1)

bar(ao', 'stacked')

xlabel('time'), ylabel('Selected number of plants'),

title('Optimization Result')

legend('Hydro power', 'Wind Power', 'Solar Power');

figure(2) 
\%subplot $(2,1,1)$

plot $(\mathrm{t}, \mathrm{cos} \mathrm{t})$, grid on

xlabel('time'), ylabel('Cost of Electricty per unit'), title('Cost of Hybrid Electricity over a day')

$\%$ subplot $(2,1,2)$

$\%$ plot(t,P_Supply,t,(P_rload),'r'),grid on

\%xlabel('time'), ylabel('Power in per unit'), title('Supply vs

Load')

\%legend('Supply','Load')

\section{REFERENCES}

[1] HOMER Energy, http://www.homerenergy.com/ software.html, Accessed Feb 2015.

[2] Motaz Amer, A. Namaane and N. K. M'Sirdi (2013). Optimization of Hybrid Renewable Energy Systems (HRES) Using PSO for Cost Reduction, The Mediterranean Green Energy Forum 2013, MGEF-13, Elsevier-Science Direct, Energy Procedia 42 (2013) 318 $-327$.

[3] Bansal, A.K., Gupta R.A., Kumar, R., (2010). Optimization of hybrid PV/Wind Energy System using Meta Particle Swarm Optimization (MPSO). IEEE, India Internaltional Conference on Power Electronics (IICPE), pp 1-7

[4] G. Naveen Ram , J. Devi Shree2 , A. Kiruthiga (2013). COST OPTIMIZATION OF STAND ALONE HYBRID POWER GENERATION SYSTEM USING PSO, International Journal of Advanced Research in Electrical, Electronics and Instrumentation Engineering, Vol. 2, Issue 8

[5] Saeid Lotfi Trazouei, Farid Lotfi Tarazouei**, Mohammad Ghiamy (2013). Optimal Design of a Hybrid Solar -Wind-Diesel Power System for Rural Electrification Using Imperialist Competitive Algorithm, INTERNATIONAL JOURNAL of RENEWABLE ENERGY RESEARCH, Vol. 03, No. 2.

[6] DEEPALI SHARMA, PRERNA GAUR, and A. P. MITTAL2 (2014). Comparative Analysis of Hybrid GAPSO Optimization Technique With GA and PSO Methods for Cost Optimization of an Off-Grid Hybrid Energy System, Taylor and Francis Group, Energy Technology \& Policy (2014), ISSN: 2331-7000, pp. $106-114$

[7] Lhassane Idoumghar, Mahmoud Melkemi, René Schott, and Maha Idrissi Aouad (2011), Hybrid PSO-SA Type Algorithms for Multimodal Function Optimization and Reducing Energy Consumption in Embedded Systems, Applied Computational Intelligence and Soft Computing, Volume 2011 (2011), Article ID 138078, 12 pages, DOI:10.1155/2011/138078

[8] Banu Y. Ekren \& Orhan Ekren. (2009). Simulation based size optimization of a PV/wind hybrid energy conversion system with battery storage under various load and auxiliary energy conditions. Econpapers. Applied Energy. Vol. 86, issue 9, 1387-1394p.
[9] Zhou Wei. (2008). Simulation and optimum design of hybrid solar-wind and solar-wind-diesel power generation systems. Hong Kong Polytechnic University.

[10] S.Ashok. (2007). Optimised model for community-based hybrid energy system. ScienceDirect, Elsevier, Renewable Energy 32.1155-1164p.

[11] Acakpovi, A., Hagan, E. B., Fifatin, F.X. 2015. Cost Optimization of an Electrical Energy Supply from a Hybrid Solar, Wind and Hydropower Plant. International Journal of Computer Applications (IJCA).

[12] Acakpovi, A., Hagan, E. B. 2013. Novel Photovoltaic Module Modeling using Matlab/Simulink, International Journal of Computer Applications (IJCA) Vol. 83, $\mathrm{N}^{\mathrm{o}} .16$, pp 27-32.

[13] Villalva, M., G., Gazoli, J.R., and Filho. E.R. 2009. Comprehensive Approach of Modeling and Simulation of a Photovoltaic Arrays. IEEE Transaction on Power Electronics. Vol.24. No.5. pp. 1198-1208.

[14] Ramos-Paja, C.A., Perez, E., Montoya, D.G., Carrejo, C.E., Simon-Muela, A., Alonso, C. 2010. Modelling of Full Photovoltaic Systems applied to Advanced Control Strategies. Columbia: Universidad Nacional de Columbia

[15] Tsai, H.L., Tu, C.S., and Su, Y.J. 2008. Development of Generalized Phottovoltaic Model Using MATLAB/SIMULINK. Proceedings on the world congress on Engineering and Computer Science. WCECS, ISBN: 978-988-98671-0-2, 6p.

[16] Khajuria, S., and Kaur, J. 2012. Implementation of Pitch Control of Wind Turbine using Simulink (Matlab). International Journal of Advanced Research in computer Engineering and technology (IJARCET), vol.1, ISSN: $2278-1323$

[17] Abbas, F. A. R., Abdulsada, M. A. 2010. Simulation of Wind-Turbine Speed Control by MATLAB. International Journal of Computer and Electrical Engineering. Vol. 2, No. 5, 1793-8163p.

[18] Acakpovi, A., Hagan, E. B. 2014. A Wind Turbine System Model Using a Doubly-Fed Induction Generator (DFIG). International Journal of Computer Applications (IJCA). Vol. 90, $\mathrm{N}^{\mathrm{o}}$.15, pp 6-11.

[19] Fuchs, E.F., Masoum, M.A.S. 2011. Power Conversion of Renewable Energy Systems. Springer. ISBN 978-14419-7978-0.

[20] Hernandez, G.A.M., Mansoor, S.P., Jones, D.L. 2012. Modelling and Controlling Hydropower plants. Springer. DOI 10.1007/978-1-4471-2291-312.

[21] Naghizadeh, R.A., Jazebi, S., Vahidi, B. 2012. Modelling Hydro Power Plants and Tuning Hydro Governors as an Educational Guideline. International Review on Modelling and Simulations (I.RE.MO.S), Vol. 5, N $\mathrm{N}^{\circ} 4$. 